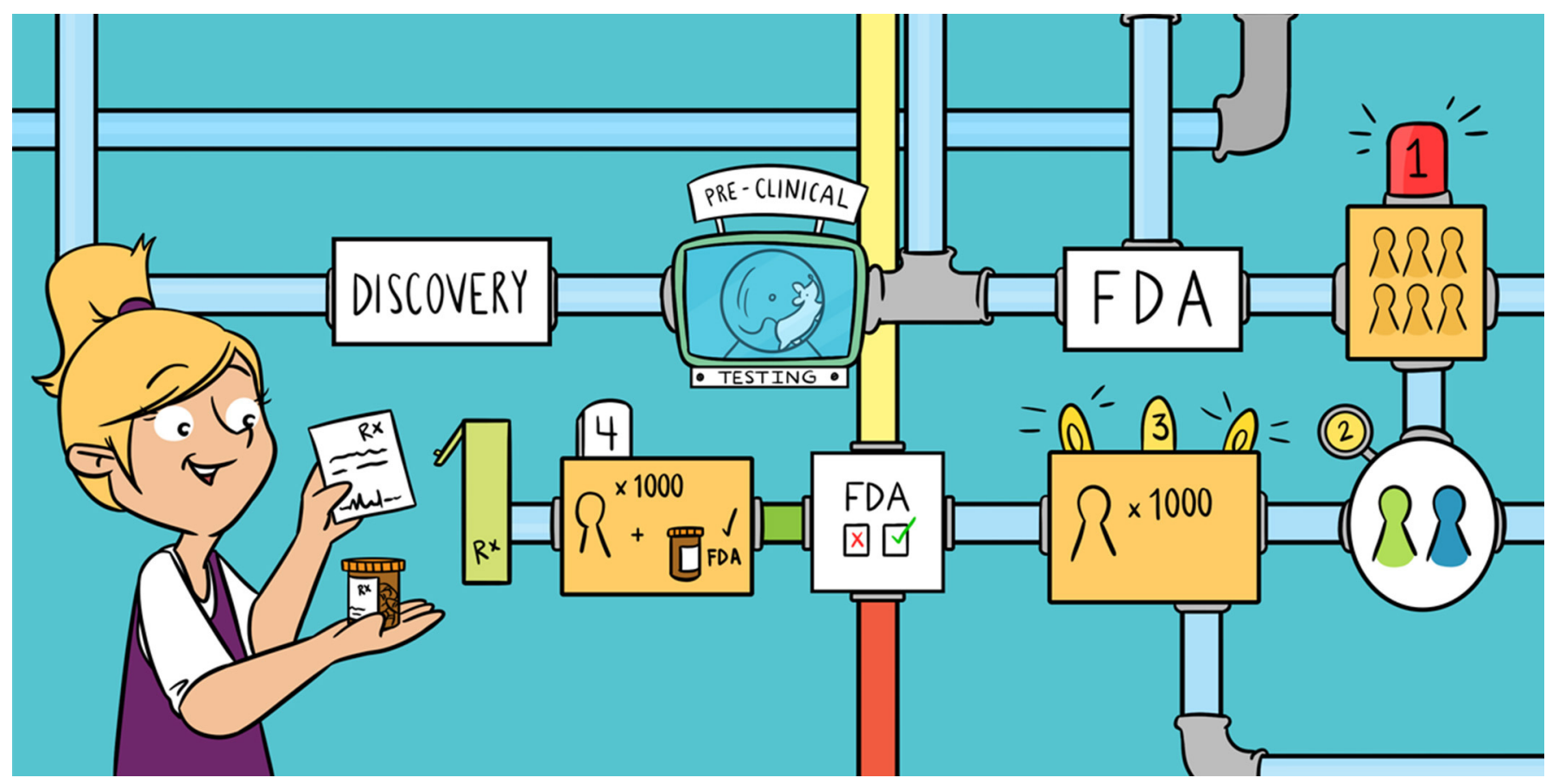

\title{
HOW DO SCIENTISTS DEVELOP ANTIBIOTICS?
}

\section{Sanskruti Karwa, Snehal Kadam and Karishma S. Kaushik*}

Institute of Bioinformatics and Biotechnology, Savitribai Phule Pune University, Pune, India

YOUNG REVIEWERS:

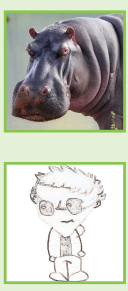

JEREMY

AGE: 10

SYLVIA

AGE: 10

Bacteria are microscopic organisms that live everywhere-even on and inside our bodies. Some are harmless, but if harmful bacteria enter our body, where they do not belong, they can cause an infection. To get rid of infections, doctors prescribe treatments with antibiotics. But how are antibiotics discovered or made? How do doctors know that the antibiotic will destroy bacteria, but not harm us? Are these antibiotics tested before we use them? In this article, we will address these questions by taking a close look at the drug development process, which is a series of steps that lead to the development of new antibiotics, among other medicines. Only treatments that pass these stages of analysis and review, which often take several years, are considered appropriate for human use, and in the case of antibiotics, are recommended for use against infections.

\section{INTRODUCTION}

Do you remember the last time you visited a doctor for a pus-filled ear infection? Or maybe it was a throat infection with swollen tonsils? 


\section{ANTIBIOTIC}

A medicine that fights bacterial infection, either by killing the bacteria or preventing their growth.

\section{BACTERIA}

Microscopic organisms that are not visible with naked eye.

\section{DRUG}

A substance that has medicinal effects when ingested or otherwise introduced into the body.

\section{DRUG}

\section{DEVELOPMENT} PIPELINE

The whole process from discovery of drug to bringing the new safe and successful drug to the market for use.

\section{FOOD AND DRUG} ADMINISTRATION

An agency within US public health service that is responsible for protecting public health by ensuring the safety and efficacy of various substances used by humans and animals. including drugs.

\section{CLINICAL TRIAL}

A type of research that studies new tests and treatments and assesses their effect on human health.
In either case, you were very likely experiencing a bacterial infection. If so, the doctor probably prescribed certain medicines, known as antibiotics, that can destroy the infection-causing bacteria.

Bacteria are tiny, microscopic organisms that exist everywhere, including in the human body (more information on these fascinating creatures can be found in these articles [1-3]). A bacterial infection results from the presence and growth of harmful bacteria on or inside the body. Antibiotics are medications (also called drugs), that kill bacteria or stop their growth. Doctors recommend antibiotics for treatment based on the location of the infection and the type of bacteria causing the infection.

As you swallow that teaspoon of cherry-flavored liquid or pop that colored pill, have you ever wondered how these antibiotics are developed? You will be surprised to know that before the antibiotic-containing syrup or pill makes it to the pharmacy and later to your house, it has been subject to a thorough scientific study. This process is known as the drug development pipeline, and it consists of a series of stages from the laboratory to the clinic. Your doctor can safely recommend a medicine to you only after it has been through all the stages of the process. These stages typically include discovery of the potential antibiotic (or any other medicine) in the laboratory, characterizing important features of the antibiotic, testing its effects on animals, and later testing its use in humans. During this process, the potential antibiotic is evaluated for key features, such as its ability to kill or prevent the growth of bacteria, safety for use in humans, interactions with other medicines, dosage and length of treatment, and optimum conditions for storage, among many other parameters. The Food and Drug Administration (FDA) is a global authority that oversees and enforces these important regulations, to ensure the safety and quality of medicines, vaccines, bandages, and other treatments.

\section{THE DRUG DEVELOPMENT PIPELINE}

As we discussed already, the development of a successful and safe antibiotic must proceed through several steps, from discovery to rigorous analysis of its activity and side effects. The entire drug development pipeline can take anywhere between 10 and 20 years, from discovery of a potential antibiotic to its license for use in humans. The pipeline can be broken down into three main steps: discovery and characterization, pre-clinical testing, and clinical trials (Figure 1).

\section{Discovery and Characterization}

In laboratories all over the world, scientists are trying to find new antibiotics. In this discovery stage, scientists test a range of compounds from plant, animal, and fungal sources for their effects on different bacteria. Today, scientists are actively collecting and testing 
Figure 1

The drug development pipeline has multiple stages, starting from drug discovery to marketing for human use. A potential antibiotic needs to successfully pass through these various stages before approval by the FDA and healthcare use. This process can take anywhere from 10 to 20 years.

\section{EFFICACY}

Effectiveness of the drug to produce desired result.

\section{MODEL ORGANISMS}

Animals that are raised to be used for laboratory testing.

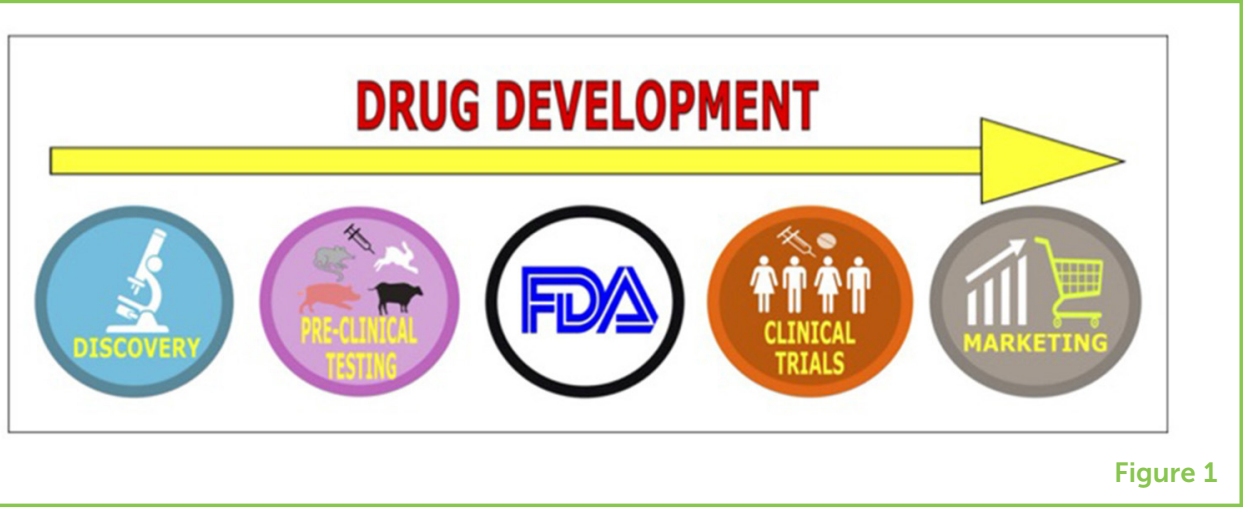

potential antibiotic sources, but the first antibiotic was discovered purely by chance by the British physician Alexander Fleming [4]! While working in his laboratory, Fleming observed a clump of fungus growing on a bacterial culture plate, and he saw that the bacteria on that plate were not able to grow in the area close to the fungus. The fungus was producing penicillin, a powerful antibiotic, that was killing nearby bacteria. Today, similar testing approaches can identify potential new antibiotics, which are then further analyzed [5]. Potential antibiotics are studied for their chemistry and structure, as well as for their biological activities, such as how effective they are at killing bacteria and their interactions with other medicines. This information is critical for the production of the antibiotic and ensures the safety, purity, and potency of the new drug. This characterization also provides important information for the company that will eventually manufacture the antibiotic, which must submit the information to the FDA for approval of the drug (Figure 1).

\section{Pre-clinical Testing}

In the next step of drug development, compounds that have shown promising results in laboratory experiments undergo another round of tests before they can be tried in humans. This step is called pre-clinical testing and it focuses on evaluating the efficacy (effectiveness) of the drug in a "real" infection (as opposed to testing in the lab) and the drug's possible toxic effects. Pre-clinical testing often involves the use of animals, such as rabbits, rats, mice, guinea pigs, hamsters, and even larger animals, such as dogs, pigs, sheep, and calves (Figure 2). These animals are called model organisms, which means they are grown to be test animals in the laboratory. They are not wild animals, pets, or abandoned animals.

Let us pause for a bit here-it must be hard for you to think of animals being used for laboratory tests. Scientists take animal testing seriously, and the scientific community is well aware of the ethical concerns of using animals for these purposes. As a result, animal testing is highly regulated and scientists and laboratories are trained to conduct this work with the highest standards of care for the animals. However, researchers are also actively working to develop alternatives to animal 
Figure 2

Scientists use various tests to study potential antibiotic efficacy and activity, such as laboratory tests and animal models. If the results of testing are promising, the drug is recommended by the FDA for further testing or clinical trials.

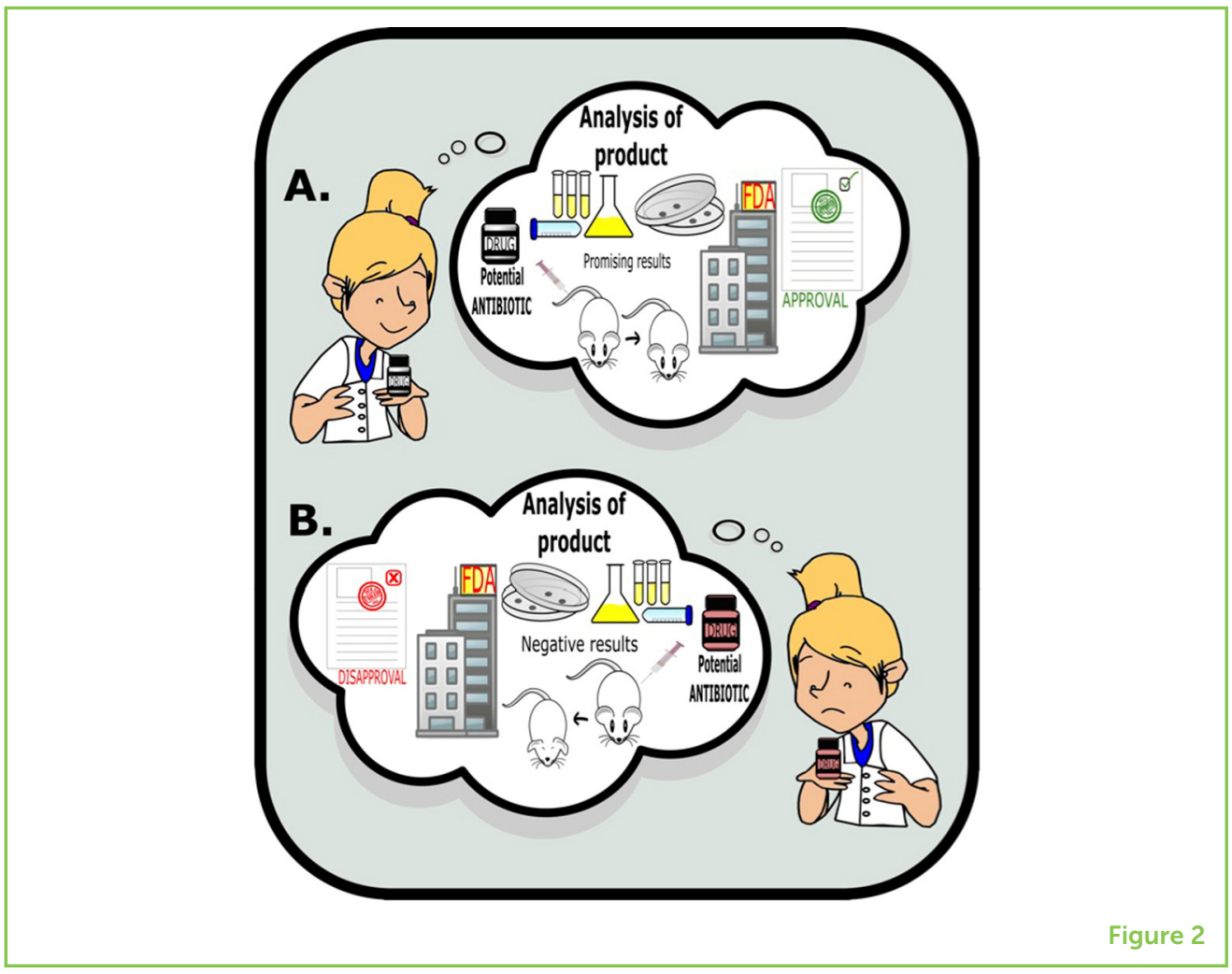

testing, by making laboratory tests closely mimic human infections. The scientific community is looking to replace animal testing with these human-like laboratory tests, but before this can become a reality, human-like laboratory tests will need to be studied in detail to make sure that they can adequately measure the safety of new drugs. Keep an eye out for these important developments!

Currently, testing with laboratory animals allows the analysis of drug features, such as antibiotic activity, safety, dosage, and toxicity in a living system, so that this information is well-understood before the drug is used in clinical trials on humans.

\section{Clinical Trials}

The last major step of the drug development pipeline is to test the drugs in humans, in what are called clinical trials (Figure 1). To take the potential antibiotic to clinical trials, an Investigational New Drug (IND) application must first be submitted to the FDA. This application is usually submitted by the company that will develop the drug. The FDA will look closely at the results from the pre-clinical testing, examine the drug's chemical structure and mechanism of action, understand the side effects and evaluate safety of the drug through its dosage and toxicity of the drug in a living system. If the FDA approves a drug developer's IND, then the drug can move on to human clinical trials [5] (Figure 2). A clinical trial typically involves four stages. 
Stage 1: The first stage involves giving low doses of the drug to a small number (maybe a dozen) of healthy people. This trial studies how the drug is absorbed and processed in the body, and any possible side effects. It mainly focuses on determining the dosage and safety of the drug for human use.

Stage 2: This stage involves two groups of people-healthy individuals and a disease group, which consists of infected people, in the case of antibiotics. The trial focuses on understanding whether the drug is effective in treating the condition of the disease group, for example whether an antibiotic actually fights infection in humans. It also focuses on understanding the exact dosage needed for the drug to work.

Stage 3: This phase involves clinical trials on hundreds to thousands of patients. In this phase, the new drug is compared with existing drugs. Patients are watched closely, and the drug trial is stopped if patients have side effects. In this phase, the safety of the drug is a priority, along with the drug's success in producing the desired result. Using data from these clinical trials, another application called a New Drug Application must then be filed with the FDA. The FDA closely examines the data obtained from the clinical trials and, based on this data, can make three choices: it can approve the drug, it can deny the drug, or it can request additional information. If approved by the FDA, the drug becomes immediately available for commercial production.

Stage 4 Clinical Trials: This stage tests new drugs approved by the FDA, in large numbers (usually thousands) of patients. This particularly looks for rare side effects (or benefits), which can be determined only in a large number of people.

\section{SO, NOW YOU KNOW!}

So, now you know that developing a new antibiotic is not easy! It is a long and rigorous process involving discovery of the drug in the laboratory, analyzing its efficacy and safety, followed by submitting an Investigational drug Application (IND) and Pre-clinical and Clinical Tests. This process is important to identify the drugs that are effective, and not allow the use of those that are not. The next time you go to the doctor's office and get a drug prescription, you may want to share your new knowledge with them!

\section{REFERENCES}

1. da Silva, G. J., and Domingues, S. 2017. We are never alone: living with the human microbiota. Front. Young Minds 5:35. doi: 10.3389/frym.2017.00035

2. Okshevsky, M., and Meyer, R. L. 2016. Big bad biofilms: how communities of bacteria cause long-term infections. Front. Young Minds 4:14. 
doi: $10.3389 /$ frym.2016.00014

3. Reches, M. 2018. Fighting bacteria: how can we prevent hospital-acquired infections? Front. Young Minds 6:43. doi: 10.3389/frym.2018.00043

4. Letek, M. 2020. Alexander Fleming, the discoverer of the antibiotic effects of penicillin. Front. Young Minds 7:159. doi: 10.3389/frym.2019.00159

5. Horien, C., and Yuan, P. 2017. Focus: drug development: drug development. Yale J. Biol. Med. 90:1.

SUBMITTED: 06 February 2020; ACCEPTED: 21 August 2020;

PUBLISHED ONLINE: 24 September 2020.

EDITED BY: Jorge Galindo-Villegas, Nord University, Norway

CITATION: Karwa S, Kadam S and Kaushik KS (2020) How Do Scientists Develop Antibiotics? Front. Young Minds 8:532921. doi: 10.3389/frym.2020.532921

CONFLICT OF INTEREST: The authors declare that the research was conducted in the absence of any commercial or financial relationships that could be construed as a potential conflict of interest.

COPYRIGHT () 2020 Karwa, Kadam and Kaushik. This is an open-access article distributed under the terms of the Creative Commons Attribution License (CC BY). The use, distribution or reproduction in other forums is permitted, provided the original author(s) and the copyright owner(s) are credited and that the original publication in this journal is cited, in accordance with accepted academic practice. No use, distribution or reproduction is permitted which does not comply with these terms.

\section{YOUNG REVIEWERS}
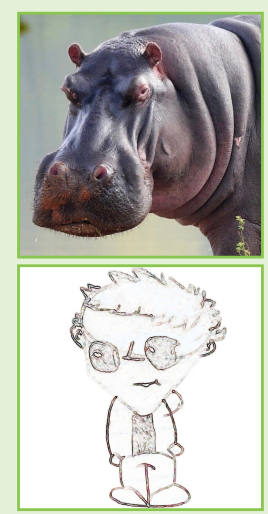

\section{JEREMY, AGE: 10}

Jeremy like to bake, play, sports, and listen to music. If he is not doing any of those things, he reads books about history, math, and science.

\section{SYLVIA, AGE: 10}

Sylvia enjoys drawing and The Simpsons, and would like to learn more about health.

\section{AUTHORS}

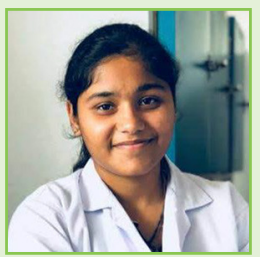

\section{SANSKRUTI KARWA}

Sanskruti is an undergraduate student studying at the Institute of Bioinformatics and Biotechnology, Savitribai Phule Pune University, India. From mycoplasma to a nerve cell: science never fails to fascinate her. Her interests in biology mainly focuses on genetics and molecular biology. She is a lawn tennis player, and in her free time, she enjoys quilling, learning different languages, and exploring different places! 


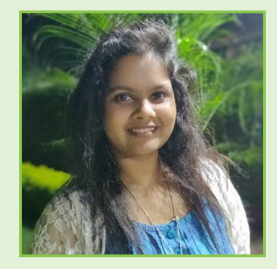

\section{SNEHAL KADAM}

Snehal Kadam is a M.S. from the Indian Institute of Science Education and Research (IISER) Pune. She currently studies wounds and wound infections in the Institute of Bioinformatics and Biotechnology, Savitribai Phule Pune University, India. Fascinated by all things bacterial, she wants to understand biofilms and host-pathogen interactions in different infections. When not in the lab, she loves reading and exploring new places and food! She also enjoys talking to young minds about science through the "Talk to A Scientist" online platform!

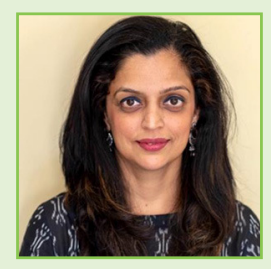

\section{KARISHMA S. KAUSHIK}

Karishma is a medical doctor and a scientist. She spent almost 15 years earning her degrees, and proudly says she enjoyed being in school! She currently leads a young and dynamic group of researchers at Savitribai Phule Pune University, India, and they explore wound infections and biofilms. Her research group has founded an interactive webinar based platform, "Talk To A Scientist," where they share science with young minds each week. Apart from her science pursuits, she loves spending time with her husband and their young son, and together they have traveled to six continents!. *karishmaskaushik@gmail.com 